\title{
Antioxidant Activity of a Geopropolis from Northeast Brazil: Chemical Characterization and Likely Botanical Origin
}

\author{
Joselena M. Ferreira, ${ }^{1}$ Caroline C. Fernandes-Silva, ${ }^{2}$ Antonio Salatino, ${ }^{2}$ \\ Dejair Message, ${ }^{1}$ and Giuseppina Negri $^{3}$
}

${ }^{1}$ Departamento de Ciências Animais, Universidade Federal Rural do Semi-Árido, Mossoró, RN, Brazil
${ }^{2}$ Departamento de Botânica, Instituto de Biociências, Universidade de São Paulo, São Paulo, SP, Brazil
${ }^{3}$ Universidade Federal de São Paulo, São Paulo, SP, Brazil

Correspondence should be addressed to Antonio Salatino; asalatin@ib.usp.br

Received 30 May 2017; Revised 27 September 2017; Accepted 8 October 2017; Published 31 October 2017

Academic Editor: Kuttulebbai N. S. Sirajudeen

Copyright (C) 2017 Joselena M. Ferreira et al. This is an open access article distributed under the Creative Commons Attribution License, which permits unrestricted use, distribution, and reproduction in any medium, provided the original work is properly cited.

\begin{abstract}
Geopropolis is a product containing wax, plant resin, and soil particles. It is elaborated by stingless bees of tribe Meliponini. Methanol extracts of sample of geopropolis produced by Scaptotrigona postica ("mandaguari") in the state of Rio Grande do Norte (RN, northeast Brazil) were analyzed for the determination of standard parameters (total phenols, total flavonoids, and radical scavenging activity) and chemical characterization by HPLC-DAD-MS/MS analysis. The sample analyzed has high contents of total phenols and flavonoids, as well as high antioxidant activity. The constituents characterized were mainly flavonols, such as quercetin methyl ethers, and methoxychalcones. Such chemical profile is similar to the composition of a green propolis from the same area of RN, which is produced by Africanized Apis mellifera, using shoot apices of Mimosa tenuiflora, popularly known as "jurema-preta." This finding provides evidence that "mandaguari" geopropolis and honeybee propolis have the same botanical origin in RN. The sharing of a plant resin source by phylogenetically distant bees (Apinae and Meliponinae) suggests that bee genetic factors play little role in the choice of plants for resin collection and that the availability of potential botanical sources plays a decisive role.
\end{abstract}

\section{Introduction}

Apidae and Meliponinae correspond, respectively, to a family and a subfamily of tropical bees. An important tribe in the group is Meliponini, whose members are known as stingless bees. There are over 300 species of Meliponini, distributed into several genera, including Melipona and Trigona. The former genus comprises about 50 exclusively neotropical species, while the former is a larger group, represented by over 130 pantropical species. They are valuable pollinators of either native or crop plants [1]. The hives of stingless bees are built as honeycombs for the larvae and as pots for honey and pollen keeping $[2,3]$.

Geopropolis is a product elaborated by stingless bees. It is similar to honeybee propolis, since both products contain plant resin and beeswax. They are distinct, however, because geopropolis contains variable content of soil material. As is the case with propolis, geopropolis is used to line the entrance of the hive and seal holes on the hive nest. Much have been published about chemistry of propolis, its botanical origin, and biological activity [4-6]. In comparison, considerably less has been done on geopropolis, in spite of the huge biological diversity of stingless bees $[7,8]$. In Brazil, geopropolis has been used for the treatment of respiratory diseases and dermatoses [9]. Brazilian geopropolis revealed antioxidant, anticancer, anti-inflammatory, and antimicrobial activities [10], while Indonesian geopropolis has cytotoxic activity against several human cancer cell lines [11]. Most papers about chemistry of Brazilian geopropolis have dealt with Melipona species. Melipona fasciculata produces different types of geopropolis: carbohydrates, triterpenes, anacardic acid, alkylresorcinols, and sugar alcohols characterize a 
geopropolis from the northeast Brazil [7], while phenolic acids, gallo- and ellagitannins, are constituents of a geopropolis from the lowlands of the state of Maranhão (western northeast Brazil) [2,3]. Melipona subnitida from the state of Paraíba (northeast Brazil) produces geopropolis containing phenylpropanoids and flavonoids [12]. Melipona scutellaris from the state of Bahia (southern northeast Brazil) produces distinct types of geopropolis, for example, a sample containing benzophenones as main constituents [13] and another one characterized by cinnamic acid esters and coumarins [8]. Flavonoid glycosides were detected in geopropolis of two Amazonian stingless bees, Melipona interrupta and $M$. seminigra [14], and phenolic compounds and terpenes were reported for a geopropolis of $M$. orbignyi from Mato Grosso do Sul (central-west Brazil) [15]. Much less has been published about geopropolis of other species of stingless bees. A geopropolis of Trigona spinipes contains triterpenes and magniferolic acid, among other constituents [9]. A geopropolis of Scaptotrigona postica from Maranhão has a peculiar chemical profile: in addition to caffeoyl-quinic acids, it contains flavone- $C$-glycosides (chiefly vicenin-2) and a pyrrolizidine alkaloid derived from retronecine [16].

Studies about botanical origin of geopropolis are scarce. Evidence has been raised that fruits of Corymbia torelliana (Myrtaceae) provide resin for the production of geopropolis by the Australian Tetragonula carbonaria (Meliponini), due to a great similarity in the methylated flavanone profiles of both materials [17].

To our knowledge, nothing has been published about the chemistry of geopropolis of Scaptotrigona from the Brazilian Semiarid, a region designated as the "drought polygon." It has been shown recently that a dark green honeybee propolis from Rio Grande do Norte (RN) is produced with shoot apices of Mimosa tenuiflora (Willd.) Poir. (Leguminosae, Mimosoideae), a plant locally known as "jurema-preta" [18]. It is a hardy and abundant species in the caatinga biome, a typical dry forest of Brazilian northeast, characterized by spiny small trees and shrubs, cacti, and euphorbs. Most caatinga plants are devoid of leaves over the long dry season, but "jurema-preta" remains green all year long. In the same area, a geopropolis with dark green color is produced by bees of Scaptotrigona postica Latreille, 1807, popularly known as "mandaguari." It is a highly adaptable and active pollinator stingless bee widespread in several parts of Brazil. Many meliponaries produce "mandaguari" pollen and propolis, the latter being reputed as having quality superior to the green propolis from southeast Brazil. The aim of the present study was to determine standard parameters (total phenolic substances, total flavonoids, and antioxidant activity) of $S$. postica geopropolis, characterize its constituents, and test the hypothesis that "jurema-preta" might be its resin source.

\section{Material and Methods}

2.1. Material. A geopropolis sample of S. postica was collected in January 2014 in the meliponary at UFERSA (Rural Federal University of the Semiarid), municipality of Mossoró, $\mathrm{RN}$ state (eastern northeast Brazil; $05^{\circ} 11^{\prime} 16^{\prime \prime} \mathrm{S} 37^{\circ} 20^{\prime} 38^{\prime \prime} \mathrm{W}$ ). Nearly $3 \mathrm{~g}$ of material was collected from three boxes, by scraping the product accumulated between the hive and its cover. The geopropolis collected is dark green and somewhat sticky, with resinous smell and moldable texture. The sample was cleaned of impurities, placed inside plastic bags, and kept in freezer.

2.2. Preparation of Ethanol Extracts. The geopropolis sample was powdered using liquid nitrogen, mortar, and pestle. Powdered material $(1 \mathrm{~g})$ was treated with $150 \mathrm{~mL}$ of ethanol in Soxhlet for $6 \mathrm{~h}$. The extract was filtered and kept overnight in a dark flask in freezer at $-20^{\circ} \mathrm{C}$. The cold extract was filtered again to eliminate wax excess.

2.3. Standard Chemical Parameters. An aliquot of $20 \mathrm{~mL}$ of the wax free extract (WFE) was evaporated to dryness under nitrogen flow and weighed for determination of total solids. Triplicates of $5 \mathrm{~mL}$ of WFE were used for determination of the contents of total phenolic substances and total flavonoids, the former by the method of Folin-Ciocalteu and the latter by the method of the aluminum chloride. The procedures were described elsewhere [19]. Reference compounds used were $p$ coumaric (total phenols) and quercetin (total flavonoids).

2.4. Antioxidant Activity. Triplicates of $5 \mathrm{~mL}$ of WFE were used for analysis of DPPH (2,2-diphenyl-1-picrylhydrazyl) free radical scavenging activity, according to Righi and collaborators [21], with modifications. Detailed procedure is available in a recent publication [18].

2.5. HPLC/DAD and HPLC-DAD-ESI-MS/MS Analyses. Aliquots of $1 \mathrm{~mL}$ of WFE were evaporated to dryness under nitrogen flow and the residue was dissolved in HPLC grade methanol to obtain solutions at $10 \mathrm{mg} \mathrm{mL}^{-1}$. The solutions were purified through $0.45 \mu \mathrm{m}$ filters. Aliquots $(10 \mu \mathrm{L})$ were analyzed by HPLC-DAD with a HPLC HP 1260 chromatograph (Agilent Technologies), using a Zorbax 5B-RP-18 column. Analysis was also carried out by HPLC-DAD-ESIMS/MS with a DADSPD-M10AVP Shimadzu chromatograph equipped with degasser, two LC-20AC pumps, CTO-20A column oven, SIL 20AC autoinjector and SPD-20A, and a reverse phase column Phenomenex Gemini C-18, protected by a guard column. The chromatograph was coupled to an esquire 2000 Plus Bruker Daltonics spectrometer, equipped with a quadrupole ion trap mass analyzer. Details of the analysis procedures, such as gas flows, oven temperatures, solvent gradients, and databases for chemical characterization of constituents, are available in a recent publication [18]. Constituents' characterization was based on UV-DAD and MS data in the negative and positive ionization modes and comparison with previously published data [22-25].

\section{Results and Discussion}

3.1. Standardization and Antioxidant Activity. The contents of soluble solids, total phenolic compounds, and total flavonoids are shown in Table 1, in addition to the minimum acceptable values given by the Technical Regulation of Propolis Identity and Quality (TRPIQ) (standards for comparison of physical 
TABLE 1: Chemical parameters $\left(\mathrm{g} \mathrm{kg}^{-1}\right)$ and DPPH radical scavenging activity $\left(\mu \mathrm{g} \mathrm{mL}^{-1}\right)$ of a sample of geopropolis of Scaptotrigona postica from Mossoró (state of Rio Grande do Norte, northeast Brazil), compared with mean values of "jurema-preta" propolis [18] and limit values of the Technical Regulation of Propolis Identity and Quality (TRPIQ) [20].

\begin{tabular}{lcccc}
\hline Sample & Soluble solids & Total phenols & Total flavonoids & EC $_{50}$ \\
\hline Geopropolis & 550 & $111.5 \pm 5.4$ & $98.5 \pm 8.6$ & $74.1 \pm 0.5$ \\
"Jurema-preta" propolis & 537 & 140 & 105 & 65 \\
TRPIQ & Minimum 350 & Minimum 50 & Minimum 5 & - \\
Quercetin & - & - & - & $7.4 \pm 0.1$ \\
\hline
\end{tabular}

and chemical characteristics of propolis produced in Brazil) [20]. All parameters analyzed comply with TRPIQ standards. As apparent in the table, they are similar to values reported for RN green propolis derived from "jurema-preta" [18] and considerably higher than the corresponding parameters of the internationally marketed green propolis from southeast Brazil [19]. The $\mathrm{EC}_{50}$ antioxidant activity of the geopropolis sample is also shown in Table 1. As expected from the similarity between RN green geopropolis and "jurema-preta" propolis, the DPPH radical scavenging capacity of both bee products is also similar. The antioxidant activity of propolis has been attributed to its phenolic profile [26].

\subsection{Chemical Characterization and Comparison with} "Jurema-Preta" Propolis. Table 2 summarizes UV-DAD and MS data in the negative and positive ionization modes. Flavonoids were characterized by UV/vis bands at 345-360 nm (band I) and 255-280 nm (band II); chalcones were characterized by bands at $340-370 \mathrm{~nm}$ (band I) and flavanones by band at $280 \mathrm{~nm}$ [22]. The characterization of methoxylated flavonoids was based on fragments generated by loss of a methoxyl radical $\left({ }^{\circ} \mathrm{CH} 3\right)$ and chalcones were characterized by fragments generated by Retro-Diels-Alder reaction [23-25]. Details about characterization of the compounds based on UV/vis, $\mathrm{MS}^{-}, \mathrm{MS}^{+}$, and sodium adducts $\left([\mathrm{M}+\mathrm{Na}]^{+}\right)$are available in the paper by Ferreira and collaborators [18].

Only phenolic compounds, virtually only flavonoids, were characterized as constituents of the analyzed extracts of geopropolis (Table 2). This observation is consistent with the exceptionally high flavonoid content shown in Table 1. Biological properties of propolis are often attributed to their flavonoid constituents. Compounds 1, 4, and $\mathbf{1 1}$ are simple flavonol aglycones. Compounds 2, 5, 7, and 9 are flavonol methyl ethers, compounds 3, 6, 8, and 13-15 are chalcones, compound $\mathbf{1 1}$ is a flavanone, and compounds $\mathbf{1 2}$ and $\mathbf{1 6}$ are flavones. Thus, the main constituents of the analyzed $S$. postica geopropolis are flavonols and chalcones. Figure 1 depicts the HPLC-DAD chromatogram of the geopropolis ethanol extract. So far the origin of resin of propolis containing chalcones has been attributed to Leguminosae species, for example, Dalbergia ecastophyllum, the plant source of Brazilian red propolis $[21,27,28]$. The main plant sources of chalcones are species of Asteraceae, Leguminosae, and Moraceae [29]. The present report of chalcones as major constituents of both geopropolis of $S$. postica and green

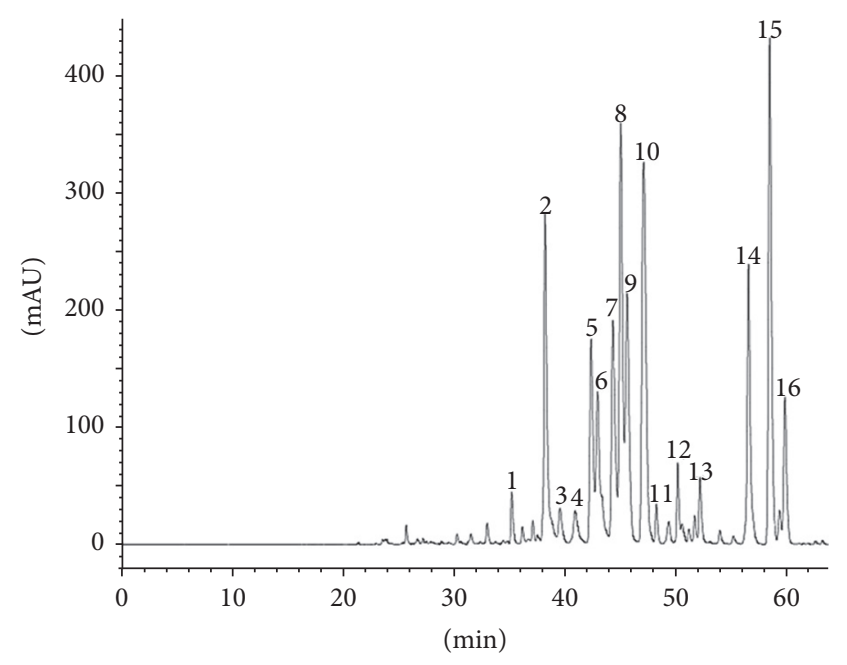

FIGURE 1: HPLC chromatogram of ethanol extracts of geopropolis of Scaptotrigona postica ("mandaguari"; Meliponini) from the meliponary at the University of Mossoró (state of Rio Grande do Norte, northeast Brazil), as characterized by HPLC-DAD. Digits of the chromatogram peaks correspond to the numbers seen in Table 2, used to indicate compounds characterized by HPLC-DAD-MS/MS.

propolis of Apis mellifera from $\mathrm{RN}$ is coherent with the hypothesis that "jurema-preta" is one of their relevant botanical sources [18]. Data of Table 2 evidences the high similarity between chemical compositions of both products. Among the 16 constituents detected in the ethanol extract of the geopropolis, 10 were also detected as constituents of the green propolis from the same area (Table 2). "Jurema-preta" is abundant in the caatinga vegetation and its pollen is an important nutritional resource for the local bees.

3.3. Comparison with Other Geopropolis. The chemical profile seen in Table 2 is distinct from the composition reported for other Brazilian geopropolis. To our knowledge, no chalcones have so far been detected in geopropolis. A geopropolis of Plebeia aff. flavocincta from $\mathrm{RN}$ has been reported to contain high contents of phenols and flavonoids, but no detailed analysis was carried out for characterization of individual constituents [30]. The geopropolis analyzed in the present work is much distinct from a geopropolis produced by Scaptotrigona postica from Maranhão [16]. It is worth observing that stingless bee colonies of the same species may produce geopropolis much distinct from one another 


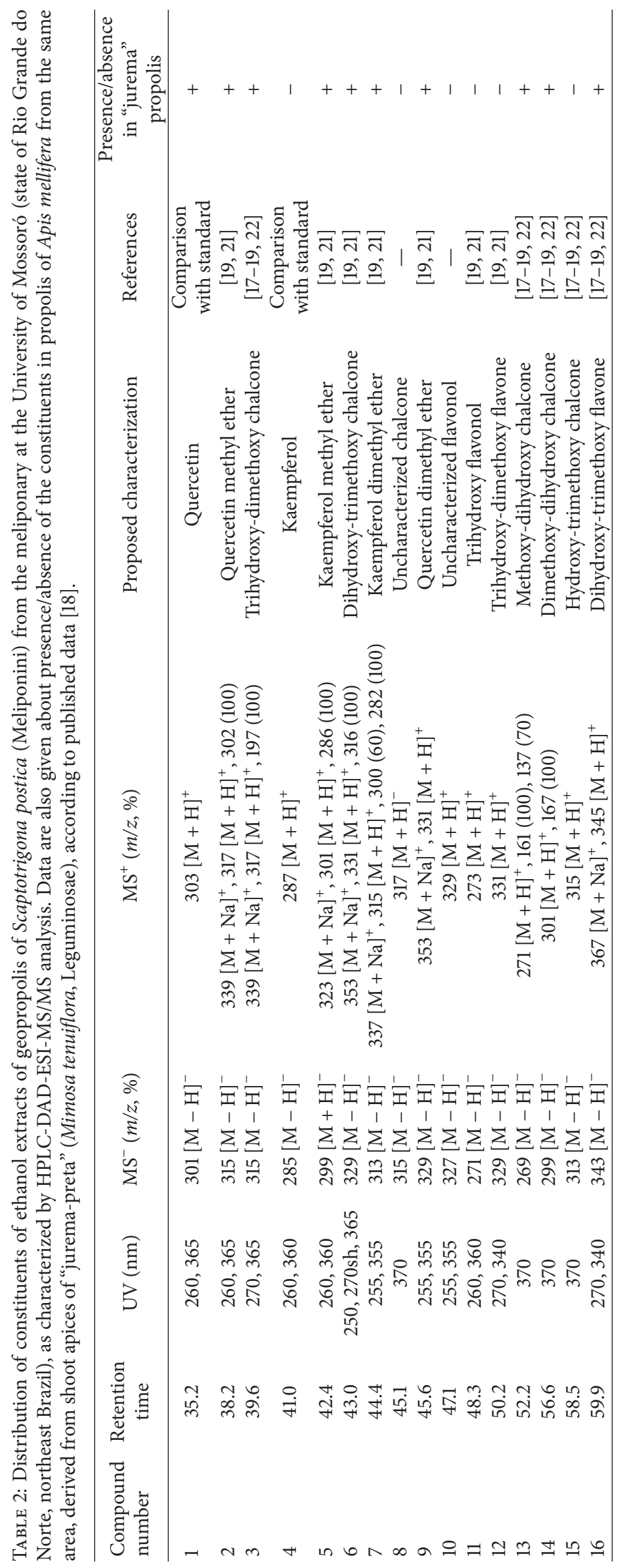


(as noted with S. postica from Maranhão and RN), while bees phylogenetically far apart (such as Scaptotrigona and Apis) may elaborate products with similar chemical composition. This observation leads to the conclusion that bee genetic factors play little role (if any) in the choice of plant sources for geopropolis and propolis production. The availability of potential resin sources is probably decisive in this regard. "Jurema-preta" plants fit well as propolis and geopropolis sources due to their abundance in the caatinga, even during the severe dry periods. In addition, they provide fresh tissues amenable to be chewed by the small and relatively delicate mandibles of the mouth apparatus of bees [31].

3.4. Perspectives. Favorable prospects regarding biological activities are suggested by the high content of flavonols and chalcones and the expressive antioxidant activity of the RN “mandaguari” geopropolis. In addition to many other biological activities, flavonols such as quercetin and isorhamnetin derivatives exhibit coronary heart disease prevention, as well as antioxidant, hepatoprotective, anti-inflammatory, and anticancer effects [32, 33]. Chalcones are flavonoids recognized as possessing many activities, such as antioxidant, anti-inflammatory, antibacterial, antifungal, cytotoxic, antitumoral, and chemopreventive activities [29, 34-36].

\section{Conclusion}

Most propolis in the commerce derives from honeybees. Some stingless bees, however, may produce propolis in amounts commercially feasible, as is the case of "jataí" (Tetragonisca angustula), from the northeast of Brazil. Bees of S. postica ("mandaguari") reveal promising prospects for becoming a relevant source of commercial geopropolis. The already reputed high quality of its geopropolis is consistent with results of the present paper, such as the high antioxidant activity and the exceptional predominance of flavonoids, including a high content of chalcones.

Taking into account the economic and social difficulties afflicting the population of northeast Brazil, including the population of $\mathrm{RN}$, the implementation of actions stimulating the production of honeybee green propolis and "mandaguari" geopropolis, both products derived from "jurema-preta," might afford benefits for the local economy, mainly during the harsher dry seasons.

\section{Conflicts of Interest}

The authors declare that they have no conflicts of interest.

\section{Acknowledgments}

The present work was funded by FAPESP (Fundação de Amparo à Pesquisa no Estado de São Paulo) (Grants 201307398-0 and 2013/21813-0). Antonio Salatino is research fellow of CNPq (Conselho Nacional do Desenvolvimento Científico e Tecnológico, Brazil).

\section{References}

[1] T. A. Heard, "The role of stingless bees in crop pollination," Annual Review of Entomology, vol. 44, pp. 183-206, 1999.

[2] R. P. Dutra, B. V. D. Abreu, M. S. Cunha et al., "Phenolic acids, hydrolyzable tannins, and antioxidant activity of geopropolis from the stingless bee Melipona fasciculata smith," Journal of Agricultural and Food Chemistry, vol. 62, no. 12, pp. 2549-2557, 2014.

[3] R. P. Dutra, A. M. C. Nogueira, R. R. D. O. Marques, M. C. P. Costa, and M. N. S. Ribeiro, "Pharmacognostic evaluation of geopropolis of Melipona fasciculata Smith from Baixada Maranhense, Brazil," Revista Brasileira de Farmacognosia, vol. 18, no. 4, pp. 557-562, 2008.

[4] V. Bankova, "Chemical diversity of propolis and the problem of standardization," Journal of Ethnopharmacology, vol. 100, no. 12, pp. 114-117, 2005.

[5] S. Huang, C.-P. Zhang, K. Wang, G. Q. Li, and F.-L. Hu, "Recent advances in the chemical composition of propolis," Molecules, vol. 19, no. 12, pp. 19610-19632, 2014.

[6] R. Silva-Carvalho, F. Baltazar, and C. Almeida-Aguiar, "Propolis: a complex natural product with a plethora of biological activities that can be explored for drug development," EvidenceBased Complementary and Alternative Medicine, vol. 2015, Article ID 206439, 29 pages, 2015.

[7] M. J. A. M. Araújo, M. C. Búfalo, B. J. Conti et al., "The chemical composition and pharmacological activities of geopropolis produced by Melipona fasciculata Smith in northeast Brazil," Journal of Molecular Pathophysiology, vol. 4, no. 1, pp. 12-20, 2015.

[8] M. G. Da Cunha, P. L. Rosalen, M. Franchin et al., "Antiproliferative constituents of geopropolis from the bee melipona scutellaris," Planta Medica, vol. 82, no. 3, pp. 190-194, 2015.

[9] M. O. Freitas, F. A. F. Ponte, M. A. S. Lima, and E. R. Silveira, "Flavonoids and triterpenes from the nest of the stingless bee Trigona spinipes," Journal of the Brazilian Chemical Society, vol. 19, no. 3, pp. 532-535, 2008.

[10] M. A. Sanches, A. M. S. Pereira, and J. E. Serrão, "Pharmacological actions of extracts of propolis of stingless bees (Meliponini)," Journal of Apicultural Research, vol. 56, no. 1, pp. 50-57, 2017.

[11] P. M. Kustiawan, S. Puthong, E. T. Arung, and C. Chanchao, "In vitro cytotoxicity of Indonesian stingless bee products against human cancer cell lines," Asian Pacific Journal of Tropical Biomedicine, vol. 4, no. 7, pp. 549-556, 2014.

[12] S. Alves De Souza, C. A. Camara, E. Monica Sarmento Da Silva, and T. M. S. Silva, "Composition and antioxidant activity of geopropolis collected by Melipona subnitida (jandaíra) bees," Evidence-Based Complementary and Alternative Medicine, vol. 2013, Article ID 801383, 5 pages, 2013.

[13] M. G. da Cunha, M. Franchin, L. C. D. Galvão et al., "Antimicrobial and antiproliferative activities of stingless bee Melipona scutellaris geopropolis," BMC Complementary and Alternative Medicine, vol. 13, article 23, 2013.

[14] E. C. C. da Silva, M. P. Muniz, R. D. C. S. Nunomura, S. M. Nunomura, and G. A. C. Zilse, "Phenolic constituents and antioxidant activity of geopropolis from two species of amazonian stingless bees," Química Nova, vol. 36, no. 5, pp. 628633, 2013.

[15] J. F. Campos, U. P. dos Santos, L. F. B. Macorini et al., "Antimicrobial, antioxidant and cytotoxic activities of propolis from Melipona orbignyi (Hymenoptera, Apidae)," Food and Chemical Toxicology, vol. 65, no. 1, pp. 374-380, 2014. 
[16] G. R. Coelho, R. Z. Mendonça, K. D. Vilar et al., "Antiviral action of hydromethanolic extract of geopropolis from Scaptotrigona postica against antiherpes simplex virus (HSV-1)," EvidenceBased Complementary and Alternative Medicine, vol. 2015, Article ID 296086, 10 pages, 2015.

[17] C. F. Massaro, M. Katouli, T. Grkovic et al., "Anti-staphylococcal activity of C-methyl flavanones from propolis of Australian stingless bees (Tetragonula carbonaria) and fruit resins of Corymbia torelliana (Myrtaceae)," Fitoterapia, vol. 95, no. 1, pp. 247-257, 2014.

[18] J. M. Ferreira, C. C. Fernandes-Silva, A. Salatino, G. Negri, and D. Message, "New propolis type from north-east Brazil: Chemical composition, antioxidant activity and botanical origin," Journal of the Science of Food and Agriculture, 2017.

[19] R. G. Woisky and A. Salatino, "Analysis of propolis: some parameters and procedures for chemical quality control," Journal of Apicultural Research, vol. 37, no. 2, pp. 99-105, 1998.

[20] “TRPIQ: Regulamento Técnico para Fixação de Identidade e Qualidade de Própolis," Portaria n. 3, Instrução Normativa n.3, Ministério da Agricultura, Pecuária e Abastecimento, Brasília, 2001, http://www.engetecno.com.br/port/legislacao/mel_ propolis.htm.

[21] A. A. Righi, T. R. Alves, G. Negri, L. M. Marques, H. Breyer, and A. Salatino, "Brazilian red propolis: unreported substances, antioxidant and antimicrobial activities," Journal of the Science of Food and Agriculture, vol. 91, no. 13, pp. 2363-2370, 2011.

[22] B. Abad-García, L. A. Berrueta, S. Garmón-Lobato, B. Gallo, and F. Vicente, "A general analytical strategy for the characterization of phenolic compounds in fruit juices by highperformance liquid chromatography with diode array detection coupled to electrospray ionization and triple quadrupole mass spectrometry," Journal of Chromatography A, vol. 1216, no. 28, pp. 5398-5415, 2009.

[23] B. Portet, N. Fabre, R. Rozenberg, J.-L. Habib-Jiwan, C. Moulis, and J. Quetin-Leclercq, "Analysis of minor flavonoids in Piper hostmannianum var. berbicense using liquid chromatography coupled with atmospheric pressure chemical ionization mass spectrometry," Journal of Chromatography A, vol. 1210, no. 1, pp. 45-54, 2008.

[24] C. Engels, D. Gräter, P. Esquivel, V. M. Jiménez, M. G. Gänzle, and A. Schieber, "Characterization of phenolic compounds in jocote (Spondias purpurea L.) peels by ultra high-performance liquid chromatography/electrospray ionization mass spectrometry," Food Research International, vol. 46, no. 2, pp. 557-562, 2012.

[25] J.-Y. Zhang, N. Li, Y.-Y. Che et al., "Characterization of seventy polymethoxylated flavonoids (PMFs) in the leaves of Murraya paniculata by on-line high-performance liquid chromatography coupled to photodiode array detection and electrospray tandem mass spectrometry," Journal of Pharmaceutical and Biomedical Analysis, vol. 56, no. 5, pp. 950-961, 2011.

[26] M. G. Miguel, S. Nunes, S. A. Dandlen, A. M. Cavaco, and M. D. Antunes, "Phenols, flavonoids and antioxidant activity of aqueous and methanolic extracts of propolis (Apis mellifera L.) from Algarve, South Portugal," Food Science and Technology, vol. 34, no. 1, pp. 16-23, 2014.

[27] A. Daugsch, C. S. Moraes, P. Fort, and Y. K. Park, "Brazilian red propolis-chemical composition and botanical origin," Evidence-Based Complementary and Alternative Medicine, vol. 5, no. 4, pp. 435-441, 2008.
[28] B. B. Silva, P. L. Rosalen, J. A. Cury et al., "Chemical composition and botanical origin of red propolis, a new type of Brazilian propolis," Evidence-Based Complementary and Alternative Medicine, vol. 5, no. 3, pp. 313-316, 2008.

[29] Z. Rozmer and P. Perjési, "Naturally occurring chalcones and their biological activities," Phytochemistry Reviews, 2014.

[30] J. B. Silva, K. M. Costa, W. A. Coelho et al., "Quantificação de fenóis, flavonoides totais e atividades farmacológicas de geoprópolis de Plebeia aff. Flavocincta do Rio Grande do Norte," Pesquisa Veterinária Brasileira, vol. 36, no. 9, pp. 874-880, 2016.

[31] A. Salatino and M. L. F. Salatino, "Why do honeybees exploit so few plant species as propolis sources?" MOJ Food Processing \& Technology, vol. 4, no. 5, 3 pages, 2017.

[32] S. Kumar and A. K. Pandey, "Chemistry and biological activities of flavonoids: an overview," The Scientific World Journal, vol. 2013, Article ID 162750, 16 pages, 2013.

[33] V. Georgiev, A. Ananga, and V. Tsolova, "Recent advances and uses of grape flavonoids as nutraceuticals," Nutrients, vol. 6, no. 1, pp. 391-415, 2014.

[34] M. D. Awouafack, P. Tane, M. Spiteller, and J. N. Eloff, "Eriosema (Fabaceae) species represent a rich source of flavonoids with interesting pharmacological activities," Natural Product Communications (NPC), vol. 10, no. 7, pp. 1325-1330, 2015.

[35] N. K. Sahu, S. S. Balbhadra, J. Choudhary, and D. V. Kohli, "Exploring pharmacological significance of chalcone scaffold: a review," Current Medicinal Chemistry, vol. 19, no. 2, pp. 209-225, 2012.

[36] P. Singh, A. Anand, and V. Kumar, "Recent developments in biological activities of chalcones: A mini review," European Journal of Medicinal Chemistry, vol. 85, pp. 758-777, 2014. 


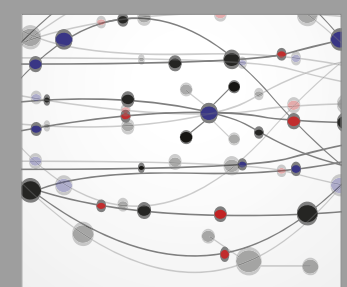

The Scientific World Journal
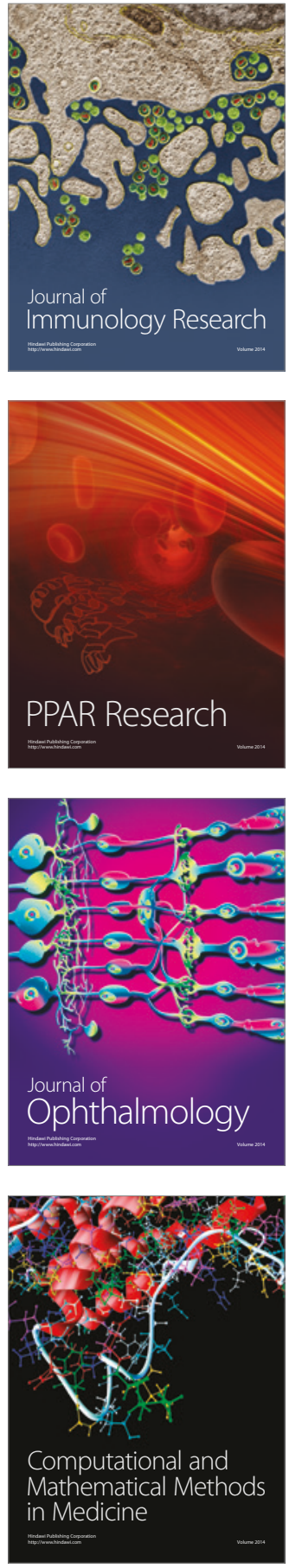

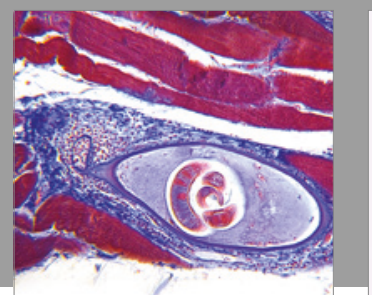

Gastroenterology Research and Practice
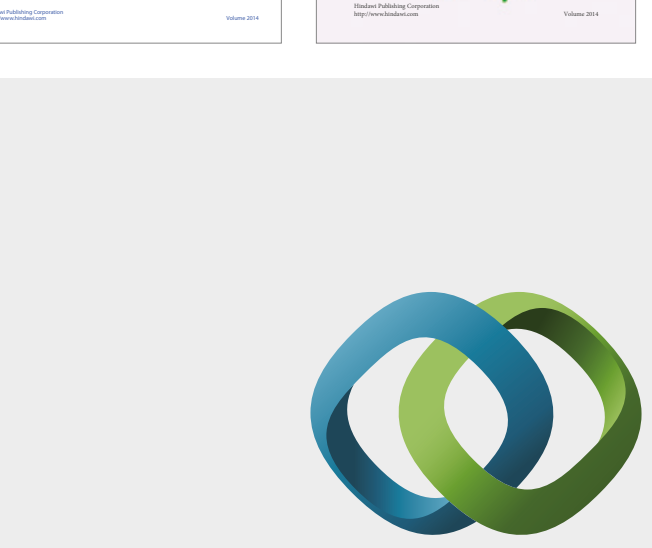

\section{Hindawi}

Submit your manuscripts at

https://www.hindawi.com
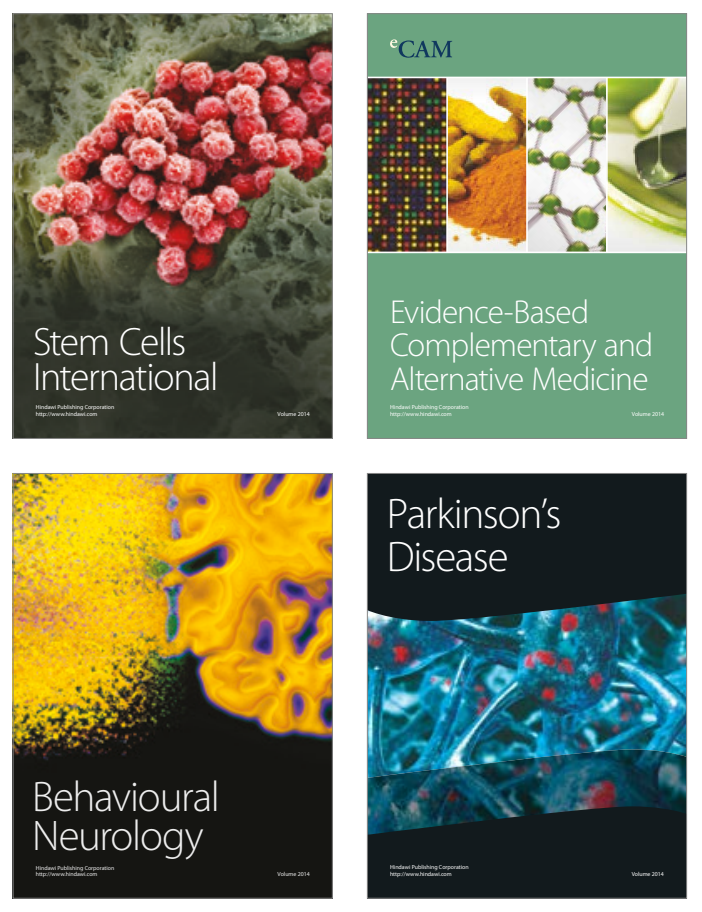
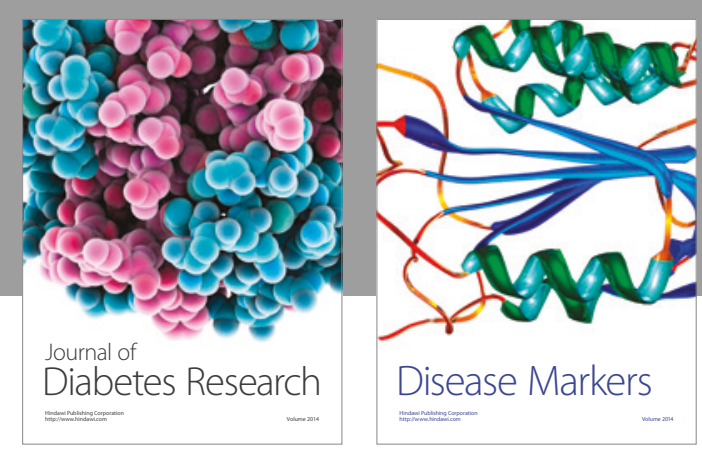

Disease Markers
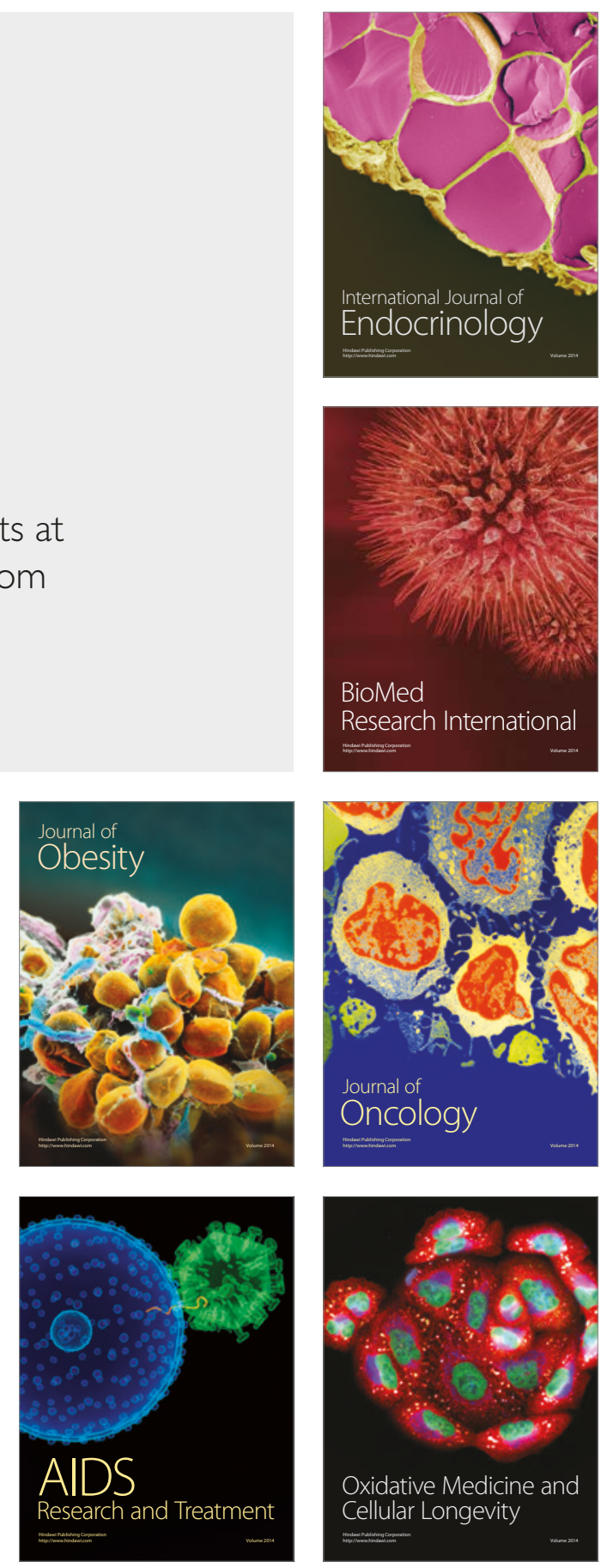